\title{
Сообщения
}

Пространственная Экономика

2005. № 2. C. 154-162

\section{Ясуси Кайто}

\section{ИСТОКИРОССИЙСКОГО ИНФОРМАЦИОННО- ТЕХНИЧЕСКОГО ОБЩЕСТВА ${ }^{\top}$}

\section{ВВЕДЕНИЕ}

В 1990 г. мир впервые услышал выражение «информационно-техническое общество» (ИТ-общество). И термин, и явление, которое он обозначает, - результат информационно-технической революции, которая, начавшись в США, сегодня стала движущей силой мирового развития.

Идея перестройки, или перехода к рыночной экономике, возникшая в Советском Союзе середины 1980-х гг., была связана с идеей гласности. Под гласностью понималась политика создания абсолютно прозрачного общества, опирающегося на свободу информации. Но хотя Восток и Запад одновременно осознали важность информации для эволюции, действовали они по-разному. Запад опирался на достижения информационно-технической революции, в то время как Восток делал попытки реформировать закрытое общество, раскрывая ранее засекреченную информацию. Тем не менее для всего мира основа создания ИТобщества была одна - магистральные сети телефонной связи (табл. 1).

Число абонентов фиксированных линейных телефонов на каждые 100 человек в Советском Союзе по сравнению с передовыми странами было не просто низким: в этой области советские технологии отставали от японских на 30 лет. Главная причина отставания цифровых систем (важнейших для магистральных систем телефонной связи) состояла в том, что западный Координационный комитет по контролю за экспортом в коммунистические страны ${ }^{2}$ препятствовал

(C) Yasushi Kaito, 2005

${ }^{1}$ Yasushi Kaito. Dawn of Information Society in Russia // Kaigai-Touyshi. JOI periodical. 2004. July. (The original version is printed only in Japanese). Перевод статьи печатается в сокращении.

2 Автор имеет в виду организацию, официально именуемую Комитет по координации экспорта стратегических товаров (между Востоком и Западом) - KОКОМ. В дальнейшем переводчик будет прибегать к указанному в этой сноске наименованию. 
Состояние телефонной связи

в Советском Союзе и Японии в 1990 г.

\begin{tabular}{l|c|c}
\hline \multicolumn{1}{c|}{ Показатель } & $\begin{array}{c}\text { Советский } \\
\text { Союз }\end{array}$ & Япония \\
\hline $\begin{array}{l}\text { Количество абонентов фиксированных } \\
\text { линейных телефонов, млн }\end{array}$ & 23 & 55 \\
\hline $\begin{array}{l}\text { Число абонентов фиксированных линейных телефонов } \\
\text { из расчета на 100 человек }\end{array}$ & 16,2 & 43,8 \\
\hline $\begin{array}{l}\text { Процентное соотношение дальних линий, переведенных } \\
\text { на цифровую систему, \% }\end{array}$ & 0,8 & 75 \\
\hline Количество международных переговоров, млн & 3,2 & 390 \\
\hline
\end{tabular}

Источник: Communications White Paper (1991); «Связьинвест»; НР.

использованию передовых технологий в этих странах. А незначительное число международных телефонных переговоров в Советском Союзе, по-видимому, объяснялось жесткими ограничениями на контакты с зарубежными странами.

\section{СТРОИТЕЛЬСТВО СЕТЕЙ ДАЛЬНЕЙ ТЕЛЕФОННОЙ СВЯЗИ}

Международные линии: создание наземных станций спутниковой связи. Спутниковая связь - один из наиболее эффективных методов передачи информации с любого конца России, территория которой простирается на 10 тыс. км. В 1980-е гг. Советский Союз передавал радио- и телепрограммы на все регионы страны из Москвы через спутники связи, которые сам же и запускал. Однако СССР имел очень небольшое число линий, находящихся под юрисдикцией Международного консорциума спутниковой связи, поощряющего совместное использование спутников разными странами. Районы обслуживания таких линий были в основном сосредоточены в европейской части территории СССР. Поэтому качество международной связи на Дальнем Востоке России, а также в окружающих регионах было неудовлетворительным. Международные линии, например в Узбекистане, были построены на базе устаревших технологий, и переговоры осуществлялись только через Москву. В 1989 г. между Ташкентом и Москвой проходила лишь 21 линия, а Россию и Азию соединяли 120 линий подводных кабелей, проложенных между Находкой и Наоецу (Япония) целых 30 лет назад, потому качество линий было низким. Более того, согласно правилам эксплуатации требовалось, чтобы все международные переговоры велись через Москву. Так, телефонный звонок из Наоецу во Владивосток сначала шел через Находку (8 тыс. км по территории Сибири - вместо того чтобы пройти менее 100 км во Владивосток), далее шел в Москву, затем возвращался через Сибирь и достигал Владивостока. Линии часто не соединялись, но даже когда соединялись, слыши- 
мость была очень плохой. А ситуация со связью в Монголии вызывала ассоциации с заброшенным и отрезанным от континента островом.

С 1990 по 1992 г. после ряда переговоров корпорация НЕК добилась разрешения на строительство наземных станций спутниковой связи в этих регионах. В Узбекистане НЕК вместе с «Митсуи и Ко» смогли получить заказ на подобное строительство. Во Владивостоке НЕК поставила систему наземной станции «Восток-Телекому», новой международной телефонной компании, образованной корпорацией «Ниссо Иваи» (сейчас - «Содзиц») вместе с KDD (сейчас KDDI) и приморским государственным департаментом связи. НЕК также поставила Монголии систему наземных станций спутниковой связи в рамках программы помощи японского правительства. Эти три наземные станции начали действовать в 1992 г., когда антенны с 16-метровым диаметром обеспечили международную передачу и прием голосовых и телевизионных сигналов.

Дальняя связь: транссибирская сеть СВЧ-связи. В 1970-х гг. корпорация НЕК поставила сети аналоговой СВЧ-связи, одну - в направлении от Москвы до Ялты, другие - от Сургута и Тикси в северных регионах. За устойчивость работы в течение более чем 20 лет в условиях крайне низких температур (-40 градусов) эти системы получили высокую оценку российского министерства связи.

В 1991 г. корпорация НЕК получила заказ на первую российскую сеть цифровой СВЧ-связи, которая должна была покрыть расстояние в 1020 км между Москвой и Санкт-Петербургом, поставку осуществили весной 1993 г. Эта система была подсоединена к Копенгагену через подводные кабели - так завершился процесс установки первых устойчивых цифровых линий связи между Москвой и Европой.

В июне того же года «Интертелеком», международный оператор дальней связи, объявил конкурс на строительство транссибирской сети СВЧ-диапазона (расстояние 7565 км), которая соединила бы Москву и Хабаровск. Необходимо было доставить передающее и принимающее оборудование, а также источники питания сети СВЧ-связи (162 станции по маршруту Москва - Омск - Новосибирск - Иркутск - Хабаровск). Распределение возможных последующих рисков предполагалось разделить с корпорацией «Сумитомо» и с немецкой компанией «Сименс АГ».

Вопрос финансирования решался с Европейским банком реконструкции и развития и «Бундеспост Финанс» в Германии, но в итоге было принято решение, что финансирование проекта обеспечит Экспортно-импортный банк Японии (сейчас Японский банк международного сотрудничества - ЯБМС), в лице которого Япония уже предлагала свою поддержку Советскому Союзу в октябpe 1991 г. Условия финансирования: если МВФ даст согласие на проведение программ экономических реформ и будет получено правительственное завере- 
ние в форме гарантийного письма. Метод финансирования, основанный на такой гарантии, стал главным фактором, определившим успех этого грандиозного проекта. Одной из причин неожиданно быстрых действий российского правительства было понимание важности создания сети дальней связи для построения рыночной экономики.

Требовалось решить еще одну проблему - снять ограничения, введенные КОКОМ.

Весной 1990 г. корпорация НЕК получила письмо-обязательство под контракт на проект размещения подводной системы волоконно-оптических кабелей в озере Байкал, но не смогла получить экспортную лицензию от японского правительства, поэтому от контракта пришлось отказаться. Ограничения же на сети СВЧ-связи не были такими строгими, как на оптические системы, а те линии дальней связи, которые проходили по территории России, не контролировались правилами КОКОМ. Тем не менее необходимо было приобрести экспортную лицензию от японского министерства международной торговли и промышленности, т. к. система была подконтрольна экспортным операциям.

Заголовок редакционной статьи, опубликованной 8 октября ведущей экономической газетой Японии «Нихон Кейдзай Симбун», гласил: «Сумитомо, НЕК и другие компании получают заказ стоимостью 200 миллионов долларов, финансируемый Экспортно-импортным банком Японии, на строительство линий дальней сети в России». 11 октября в Москве корпорация Сумитомо, корпорация НЕК и российская компания «Интертелеком» подписали контракт.

Его действие должно было начаться только после того, как соглашение о займе вступит в силу и будет получен 15 -процентный первоначальный платеж (в это время Россию контролировал МВФ). Несмотря на введение многочисленных ограничений, благодаря упорству Экспортно-импортного банка Японии и представителей правительств обеих стран, 6 июля 1994 г. соглашение о займе было подписано. 28 июля правительственное гарантийное письмо было отправлено, и первая часть платежа получена. Министерство международной торговли и промышленности сняло ограничения, введенные КОКОМ в конце января 1994 г. А вскоре, символизируя окончание холодной войны, КОКОМ распался: это был последний крупный проект, утвержденный им.

Благодаря поддержке сотрудников Экспортно-импортного банка Японии вскоре началась поставка сверхвысокочастотного оборудования, производимого на заводе Фукусима корпорации НЕК. Проект был закончен в срок, в конце 1995 г., и 14 марта 1996 г. в Москве президентом Ельциным была назначена торжественная церемония, посвященная его успешному окончанию.

В результате мощность линий связи (число телефонных линий) резко уве- 
личилась с 1000 аналоговых каналов до 11500 цифровых каналов. Корпорация НЕК поставила этот вид сверхвысокочастотных телефонных сетей в более чем сотню стран, но именно этот проект был назван первым, последним и единственным проектом такого масштаба.

Вскоре после этого корпорация НЕК в сотрудничестве с корпорацией Сумитомо заключили сделку на строительство волоконно-оптических передающих линий: это строительство должно было вестись через всю Россию на собственные средства корпораций. Корпорация НЕК также смогла принять участие в строительстве двух главных сетей дальней передачи (сверхвысокочастотной и волоконно-оптической линий) протяженностью в 10 тыс. км от восточной до западной границы России. Сегодня сети - основные действующие международные линии, связывающие Россию с Азией и Европой и соединяющие крупные города России. Отметим, что требования к качеству международных линий очень высоки: в экстренных случаях, когда связь не должна разъединяться, волоконнооптическая сеть используется как главная передающая сверхвысокочастотная сеть, выполняющая функцию резервной системы. Эта огромная цифровая опорная линия стала в России «катализатором» перехода телефонной сети на цифровой формат и образования российского ИТ-общества.

21 млрд иен, предоставленные Экспортно-импортным банком Японии в качестве экспортного кредита для транссибирской сверхвысокочастотной сети дальней связи, выплачивались без задержек. Насколько известно, оплата была произведена в срок, 31 октября 2001 г. Проект оптической передачи, финансированный корпорациями «Сумитомо» и НЕК, почти полностью был оплачен в апреле 2004 г.

Создание совместного предприятия наукоемкой технологии НЕКНЕВА. Поясним: инфраструктуру связи можно разделить на три основные категории: связь с другими странами через международные линии; через междугородные телефонные линии, соединяющие крупные города на территории одной страны; внутригородские линии, связывающие абонентов одного города.

В январе 1997 г. российский комитет по информации и электросвязи (бывшее министерство связи) уведомил местные региональные телефонные компании, что начиная с февраля все закупки коммутационного оборудования ограничиваются только аппаратурой местного производства. Узнав об этом решении, НЕК объединилась с корпорацией «Сумитомо» и с компанией «Мицуи и Ко» и организовала компанию НЕКНЕВА - производителя коммутационного оборудования. Российским партнером выступила инвестиционная компания «Телекоминвест» - филиал Петербургской телефонной сети (ПТС). НЕКНЕВА, первое совместное наукоемкое японско-российское предприятие, начало свою деятельность осенью 1997 г. Компания вышла на хорошую стартовую позицию в 1998 г. (благодаря, в частности, нескольким выгодным зака- 
зам), но августовский дефолт и последовавший за ним валютно-финансовый кризис нанесли ей ощутимый урон. НЕКНЕВА действовала в условиях обменного курса 5,9 руб. за доллар. В результате же резкого обесценения рубля и перехода курса на уровень 20,65 руб. за доллар компания понесла потери в твердой валюте, составившие 7 млн долл. в 1998 г. и 2,5 млн долл. в 1999 г., - это был чувствительный удар по компании с капиталом в сумме всего 6 млн долл. Тем не менее, благодаря усилиям японских и российских партнеров, а также поддержке созданного к тому времени Японского банка международного сотрудничества, начиная с 2000 г. ситуация улучшалась, ожидалось, что в 2004 г. объем продаж компании достигнет 33 млн долл. В настоящее время НЕКНЕВА владеет $14 \%$ всего рынка цифрового коммутационного оборудования в России.

Производители средств электрической связи во всем мире вынуждены бороться за выживание: в их отрасли технические инновации совершенствуются с бешеной скоростью. Поэтому НЕКНЕВА продолжает диверсификацию основной продукции и переориентирует интересы с телефонного коммутационного оборудования на оборудование для Интернета и на рынок мобильных телефонов, популярность которых стремительно растет.

Корпоративные сети. Кроме систем для российских телефонных компаний, НЕК создает и корпоративные системы. Например, в 1997 г. был получен заказ от Центрального банка России на разработку проекта по созданию спутниковой информационной сети. Все межбанковские сделки в стране ведутся через расчетный центр при ЦБ. А система проведения расчетов и других сделок между городскими банками была разработана с использованием более чем 800 сверхкомпактных наземных станций спутниковой связи, размещенных в филиалах по всей стране. Плюс к этому в 2000 г. завершен проект сети данных, позволяющей отслеживать грузы и поезда, идущие по сибирской железной дороге, на территории восточнее Уральских гор.

\section{РОССИЙСКАЯ ПОЛИТИКА РАЗВИТИЯ СВЯЗИ}

Эксплуатация средств связи. В советскую эпоху за эксплуатацию систем связи отвечало министерство связи. С рождением новой России на территории страны было создано 86 региональных телефонных компаний, связанных друг с другом через «Связьинвест», находящийся в подчинении министерства связи. Для повышения эффективности сети эти 86 компаний позднее объединили в семь комплексных региональных телефонных компаний.

Одной из компаний, собранных под этим общим «зонтиком», является «Ростелеком» (бывший «Интертелеком»), предоставляющий услуги международной и междугородной связи. Три другие крупные компании, вышедшие из-под государственной опеки, предоставляют услуги пользования мобильными теле- 
фонами внутри страны. Частные корпорации стали появляться на рынке корпоративных услуг простой и высокоскоростной связи, а что касается услуг в области фиксированных телефонов, то предполагается, что правительство будет твердо придерживаться какое-то время той политики, которую оно уже начало проводить в этой сфере.

Плата за услуги связи. За мобильные и домашние телефоны в Японии платится фиксированная сумма плюс дополнительный сбор, который зависит от объема использования. В России плата за домашний телефон (с фиксированной линией) в разных регионах разная. Но большинство абонентов продолжают платить всего около четырех долларов в месяц, независимо от того, как часто они пользуются телефонами. Эта система сборов (единый тариф) гарантирует низкую стоимость тех составляющих инфраструктуры, которые связаны с ценой на воду, бензин и телефон (электричество оплачивается по показаниям счетчика), и представляет собой пережиток коммунистического периода, защищавшего людей с низкими доходами (даже в Китае плата за телефон зависит от частоты пользования телефоном).

В рамках систем такого типа руководить телефонными компаниями, сгруппированными под «зонтиком» «Связьинвеста», трудно. Поэтому здесь не ожидается обновление инвестиций, нацеленных на расширение мощностей или на увеличение эффекта от инвестирования. На встрече по обмену мнениями между японскими и российскими провайдерами связи в Токио в марте 2004 г. было заявлено, что в результате усилий руководства компании «Связьинвест» ежегодная прибыль из расчета на одну линию выросла приблизительно до 5040 руб. (около 170 долл. США). Эта цифра низка даже по сравнению с ситуацией в развивающихся странах. Ожидать дальнейшего повышения рентабельности можно только при условии расширения объема мощностей и повышения качества услуг.

Отраслевая политика. Как правило, при проведении политики поощрения местной продукции импортные пошлины на отдельные детали более низкие, чем импортные пошлины на готовую продукцию. В России же наблюдалось обратное: налоги на отдельные компоненты коммуникационного оборудования были выше, чем на готовый продукт. Пока все материалы не изготавливались на территории одной страны (а в России они не изготавливались), такая тарифная политика не стимулировала производство местной наукоемкой и высокотехнологичной продукции - ее выпускали за рубежом. В настоящее время тарифные ставки на все детали снижены примерно до уровня ставки на законченный продукт (5\%). Тем не менее правительственная политика, в том числе и в сфере импортных пошлин, нацеленная на поощрение развития высокотехнологичных отраслей промышленности, в России все еще не имеет прочной базы.

При этом Китай, оказавшийся в международной изоляции после событий 
на площади Тянанмень в 1989 г., уже в 1990-х гг. продемонстрировал миру новую политику реформ и либерализации. Он стал привлекать все виды капитала из-за рубежа, перенимать технологию у промышленно развитых стран, укреплять базовую промышленность, поощряя развитие поддерживающих отраслей. И это в конечном итоге позволяет ему стать производственной базой для всего мира.

Ключ к российскому бизнесу - финансирование. Ключ к успеху в реализации многочисленных проектов строительства магистральных телефонных сетей не столько в новых технологиях, сколько в организации финансирования. Необходимо отметить, что здесь существенную финансовую помощь оказывал и оказывает Японский банк международного сотрудничества (табл. 2).

Таблица 2

Проекты, финансируемые ЯБМС

\begin{tabular}{l|l|c}
\hline \multicolumn{1}{c|}{ Вид финансирования } & \multicolumn{1}{|c}{ Проект } & $\begin{array}{c}\text { Год } \\
\text { выполнения }\end{array}$ \\
\hline $\begin{array}{l}\text { Рамки экспортного кредита } \\
\text { на поддержку России }\end{array}$ & Транссибирская сверхвысокочастотная сеть & 1994 \\
\hline Кредит поставщикам & $\begin{array}{l}\text { Цифровые переключатели для МТС-информ } \\
\text { (Московской телефонной компании) }\end{array}$ & 1998 \\
\hline $\begin{array}{l}\text { Двухэтапный заем ВТБ } \\
\text { крупному российскому } \\
\text { коммерческому банку) }\end{array}$ & $\begin{array}{l}\text { Сеть волоконно-оптических линий передачи } \\
\text { для «Ростелекома» }\end{array}$ & 2003 \\
\hline $\begin{array}{l}\text { Кредит для финансирова- } \\
\begin{array}{l}\text { ния долгосрочных зарубеж-- } \\
\text { ных вложений }\end{array}\end{array}$ & $\begin{array}{l}\text { Кредит для финансирования долгосрочных } \\
\text { вожений в осуществление инвестиций } \\
\text { Компании НЕК - компании НЕКНЕВА }\end{array}$ \\
\hline $\begin{array}{l}\text { Прямая ссуда российской } \\
\text { частной компании }\end{array}$ & $\begin{array}{l}\text { Сеть сверхвысокочастотных линий для } \\
\text { «Ростелекома» }\end{array}$ & 2003 \\
\hline
\end{tabular}

ЯБМС будет продолжать активно поддерживать идею расширения корпоративного и структурного финансирования проектов и частных телефонных компаний, получающих прибыль в валюте.

\section{ЗАКЛЮЧЕНИЕ}

В какой бы стране человек ни жил, ему нет дела до того, кто именно занимается созданием инфраструктуры сети телефонной связи, и этот вид деятельности представляется простым. Но для России, которая вступила в сложный период перехода от социалистической экономики к рыночной, в то время как остальной мир последние 10-12 лет превращается в общество информационных технологий, строительство магистральных сетей дальней связи - актуальные и крайне важные национальные проекты. Нужно отметить, что Япония, 
благодаря совместным усилиям государственного и частного секторов, активно и точно по графику предоставляла капитал и технологии для этих проектов.

Сравнение данных по телефонизации России на конец декабря 2003 г. с данными 1990 г., приведенными в начале статьи, показывает значительное увеличение скорости перехода к аналоговым технологиям и числа международных телефонных переговоров (табл. 3). Что касается мобильных телефонов, то услуги всеевропейской МСМТС (Мировой системы мобильной телефонной связи) начали действовать в Европе в 1992 г., а японский цифровой формат ИЦС (индивидуальный цифровой сотовый) впервые появился в Японии в 1993 г. Поэтому цифры, относящиеся к этим услугам, не были включены в первую таблицу.

Таблица 3

Основные данные о телефонной связи в России на конец декабря 2003 г.

\begin{tabular}{|c|c|}
\hline Показатель & Количество \\
\hline Абоненты фиксированных линейных телефонов & $\begin{array}{c}34,1 \text { млн } \\
(22,7 \text { абонента на } 100 \text { человек) }\end{array}$ \\
\hline Абоненты мобильных телефонов & $\begin{array}{c}36,1 \text { млн } \\
\text { (24,1 абонента на } 100 \text { человек) }\end{array}$ \\
\hline Доля цифровых форм (в дальних линиях передач) & Около $30 \%$ \\
\hline Международные переговоры & Около 260 млн \\
\hline
\end{tabular}

Из четырех стран, представляющих будущие рынки роста (Бразилия, Россия, Индия и Китай - недавно они стали обозначаться аббревиатурой БРИК), Индия и Китай показывают выдающиеся результаты развития бизнеса и отраслей ИТ частного и государственного секторов. По данным Всемирного экономического форума (октябрь 2003 г.), по этим показателям Китай был на 44-м, Бразилия - на 54-м, Индия - на 56-м месте, в то время как Россия оказалась на никем не оспариваемом 70-м месте, т. е. в самом конце этого списка.

Сегодня мир стремительно меняется. Никакие границы не могут помешать его превращению в наукоемкое общество ИТ, которое можно назвать и обществом знаний, ведь добавленная стоимость, что вносит каждый гражданин, его базовое требование. В этом смысле российские человеческие ресурсы неограниченный потенциал: Россия, при соответствующих политике и организации, в состоянии продемонстрировать большие возможности и как нация ИТ способна превзойти даже Индию и Китай.

Перевод с английского Р. П. Кучерявенко

(C) Кучерявенко Р. П., перевод с англ., 2005 